\title{
CORREÇÃO GRANULOMÉTRICA DE SOLOS PARA APLICAÇÕES EM ESTRADAS FLORESTAIS: ESTUDO DE CASO COM SOLOS DA CENIBRA ${ }^{1}$
}

\author{
Mario Sérgio de Souza Almeida², Dario Cardoso de Lima², Carlos Alexandre Braz de Carvalho ${ }^{3}$, Carlos
} Cardoso Machado ${ }^{3}$, Paulo Sérgio de Almeida Barbosa ${ }^{3}$ e Claudio Henrique de Carvalho Silva ${ }^{3}$

\begin{abstract}
RESUMO - Este artigo apresenta um procedimento para estudo do comportamento mecânico de três solos oriundos da empresa CENIBRA S. A., localizada na cidade de Belo Oriente, Minas Gerais, Brasil, para fins de emprego em revestimento primário, reforço de subleito e sub-base de estradas florestais, classificados como argila amarela, argila vermelha e areia. Empregou-se, nesta investigação, a técnica de estabilização mecânica de solos com correção granulométrica. O programa de ensaios de laboratório englobou o uso de várias composições percentuais de solos, com base na mistura entre dois deles, de modo a obter um produto final eficiente para aplicações nas estradas florestais da CENIBRA S. A. Trabalhou-se com os percentuais de 60, 70 e $80 \%$ de areia e de 20, 30 e 40\% das argilas nas composições das misturas, compactando estas na energia do ensaio Proctor Modificado. A melhor resposta mecânica foi obtida pela mistura de $80 \%$ de areia e $20 \%$ de argila amarela, com capacidade de carga representada pelo ISC de $63 \%$.
\end{abstract}

Palavras-chave: Estabilização de solos, Estradas florestais e Estabilização mecânica via correção granulométrica.

\section{GRANULOMETRIC COMPOSITION OF SOILS FOR FOREST ROADS APPLICATIONS: CASE STUDY APPLIED TO CENIBRA SOILS}

\begin{abstract}
This paper presents a procedure for studying the mechanical behavior of three soils from the cellulose company CENIBRA S. A. located in the city of Belo Oriente, the state of Minas Gerais, Brazil, to be used as a surface course, sub-grade reinforcing layer and sub-base on forest roads. The mechanical stabilization technique named textural proportioning was used throughout the study. The laboratory testing program encompassed the use of different amounts of soils in order to determine the most efficient combination of two of them to be used in the CENIBRA S. A. forest road system. Soil mixtures were produced using sand contents of 60, 70 and $80 \%$ and clayey soils contents of 20,30 and $40 \%$. Soils and mixtures specimens were compacted at the modified Proctor compaction effort. The best mechanical response was associated to the $80 \%$ sand and $20 \%$ yellow clay mixture, which presented bearing capacity via ISC of $63 \%$.
\end{abstract}

Keywords: Soil stabilization, Forest roads and Mechanical stabilization via textural proportioning..

\section{INTRODUÇÃO}

Na fase construtiva de uma estrada, nem sempre o engenheiro encontra solos satisfatórios tecnicamente ao longo de sua extensão, para serem empregados nas camadas do pavimento. Nos últimos anos, tem-se tornado frequente o uso de material oriundo de locais distantes, onerando sobremaneira a obra. Nesses casos, uma solução eficiente é o emprego de técnicas de estabilização dos solos.
Através dos recursos das técnicas de estabilização, é possível utilizar um solo que, por si só, não apresenta qualidades satisfatórias para emprego em dada camada do pavimento rodoviário. Do ponto de vista granulométrico, se for feita uma separação e a subsequente mistura de algumas de suas frações, poder-se obter material granulometricamente satisfatório para emprego em dada camada do pavimento. Alternativa mais simples para corrigir a granulometria de um solo

\footnotetext{
${ }^{1}$ Recebido em 21.12.2007 e aceito para publicação em 25.08.2010.

${ }^{2}$ Departamento Nacional de Infraestrutura de Transportes, DNIT, Brasil. E-mail: < declima@ufv.br>.

${ }^{3}$ Universidade Federal de Viçosa, UFV, Brasil. E-mail: <machado@ufv.br>.
} 
é misturá-lo na forma em que se encontra na natureza com outro que, também, isoladamente, não satisfaz as exigências de projeto, de modo a produzir um novo material que venha a atender a determinadas especificações construtivas, sob os prismas granulométrico, de plasticidade e de comportamento mecânico. Essa técnica se denomina correção granulométrica.

Neste artigo, aborda-se a produção de solos com diferentes granulometrias a partir de dois solos, respectivamente de texturas arenosa e argilosa, com o objetivo de determinar uma composição granulométrica ideal que leve a um produto com maior capacidade de carga, para fins de emprego dessas misturas em pavimentos rodoviários florestais.

\section{REVISÃO DE LITERATURA}

Geotecnicamente, estabilizar um solo consiste na utilização de processos tecnológicos que modifiquem alguns de seus parâmetros de engenharia, de modo a atender a demandas técnicas específicas. Para esse fim, existem várias técnicas de estabilização, quais sejam: mecânica, química, térmica e elétrica. Na geotecnia brasileira, as duas primeiras modalidades são comumente empregadas, com um direcionamento para a construção de rodovias (LIMA et al., 2003; TRINDADE et al., 2005; VELTEN et al., 2006). Neste artigo, abordou-se a estabilização mecânica de solos com correção granulométrica.

Segundo Lima (1981), normalmente se estuda o solo como se fosse constituído de frações granulares ou finas. As frações granulares são facilmente desagregadas por ações abrasivas do tráfego e erosivas da água. As frações finas, englobando silte e argila que são partículas com diâmetros inferiores a 0,074 mm, segundo a escala granulométrica adotada pelo Departamento de Infraestrutura de Transportes (DNIT, 2006), quando absorvem água são muito deformáveis devido à sua baixa resistência ao cisalhamento. Assim, quando os solos se encontram numa dessas situações, é comum misturarem-se materiais granulares e finos em quantidades pré-definidas, de modo a obter um produto com propriedades de engenharia adequadas para aplicações em estradas.

Essas ideias básicas levaram ao desenvolvimento de duas técnicas de correção de solos para fins rodoviários, quais sejam: (i) procurou-se associar a qualidade da mistura a um valor máximo de sua massa específica (hipótese de graduação ideal), partindo-se da premissa de que a maior densidade geralmente está associada à maior resistência mecânica; (ii) buscou-se visualizar o solo como um corpo constituído das frações denominadas ligante e agregado, procurando-se, em separado, um máximo de densidade para cada uma das partes (hipótese de ligante-agregado).

Miller e Sowers (1957), analisando o efeito das frações ligante e agregado de um solo no seu comportamento mecânico, quanto aos parâmetros geotécnicos coesão e ângulo de atrito interno, observaram que há quatro fases estruturais que descrevem o seu comportamento. Na primeira fase, a fração agregado apresenta contatos pontuais; na segunda, alguns contatos entre os grãos são realizados em zonas muito compactas; na terceira, os contatos passam a ser feitos progressivamente pela fração ligante; e, na quarta fase, a fração agregado flutua em uma massa de ligante compactado. A Figura 1 ilustra o comportamento mecânico de várias misturas de ligante e agregado em função dos seus parâmetros de resistência ao cisalhamento (coesão e ângulo de atrito) e das suas capacidades de carga.

Ressalta-se, no entanto, que há dificuldade de se antever o comportamento de um solo sob o prisma da combinação ligante-agregado, pois o comportamento do ligante na mistura pode não ser o mesmo do ligante isolado. Com base nessa constatação, regras empíricas fundamentadas nessas hipóteses, mas com o respaldo de ensaios de laboratório, foram propostas por técnicos rodoviários para representar o comportamento de misturas estabilizadas. Nesse sentido, uma técnica bastante difundida no meio rodoviário consiste na definição de uma granulometria adequada para determinada finalidade de engenharia, origem de várias das especificações construtivas rodoviárias em vigor, podendo-se referir, nesse caso, à graduação proposta por Fuller-Talbot e aqui representada pela equação 1(SOUTO SILVEIRAe SILVEIRA, 1964). Nessa equação, $p$ representa a porcentagem em peso do material que passa na peneira de diâmetro d; $d$ simboliza o diâmetro da peneira em questão; $D$ refere-se ao diâmetro da maior partícula; e $n$ representa o expoente que pode ser adotado como: (i) $\mathrm{n}<0,4$ (misturas com muitos finos); (ii) 0,4£ n $£ 0,6$ (misturas densas); e (iii) $\mathrm{n}>0,6$ (misturas abertas). 


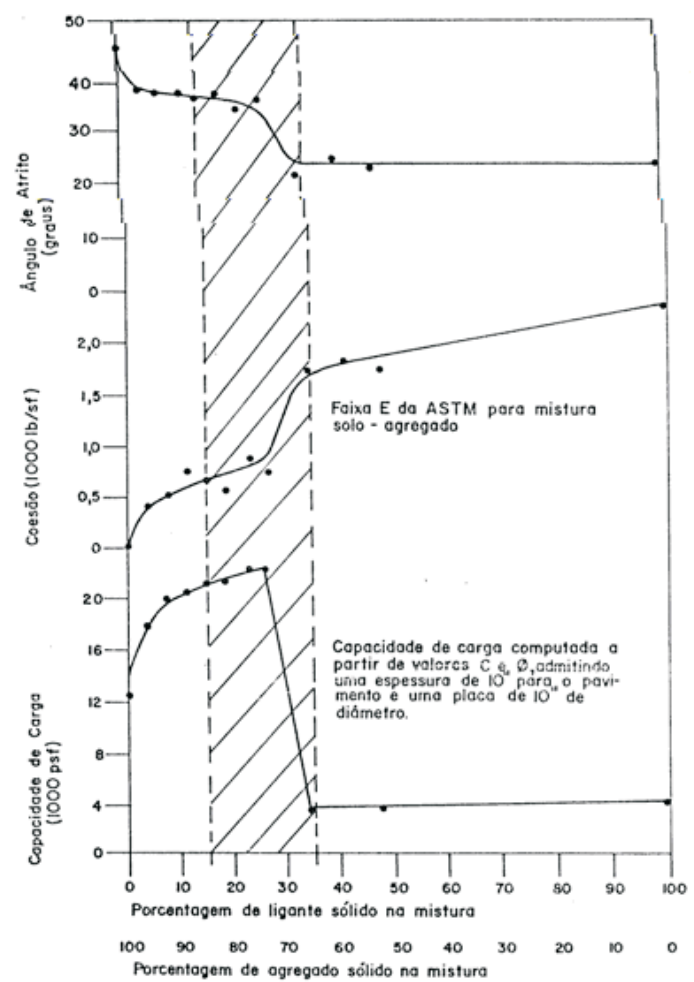

Figura 1-Parâmetros de resistência ao cisalhamento e capacidade de carga de misturas de solo-agregado para várias proporções de ligante e agregado, segundo Miller e Sowers (1957).

Figure 1 - Shear strength parameters and bearing capacity of different combinations of soil-aggregate mixtures according to Miller and Sowers (1957).

$$
\mathrm{p}=100\left(\frac{\mathrm{d}}{\mathrm{D}}\right)^{\mathrm{n}}
$$

Portanto, a partir da partícula de maior diâmetro D de um solo ou material de construção, pode-se traçar uma curva granulométrica para determinada finalidade de engenharia, sendo de grande interesse para fins rodoviários as misturas densas. Sob essa ótica, fixada uma granulometria de projeto, o problema em questão consiste em encontrar um material que atenda à granulometria exigida, a partir de outros materiais disponíveis. Essa técnica é denominada correção granulométrica.

\section{MATERIAL E MÉTODOS}

\subsection{Material}

Neste estudo, trabalhou-se com três solos oriundos da área da empresa CENIBRA S.A. (Figura 2), em Belo Oriente, MG, Brasil, comumente empregados como camadas de melhoria de subleito de trechos de estradas florestais. Dois desses solos apresentam textura argilosa, sendo um de coloração vermelha e outro de coloração amarela; o terceiro solo é uma areia de rio. Para fins de estudo, esses solos foram denominados, respectivamente, argila vermelha, argila amarela e areia.

\subsection{Métodos de ensaios de laboratório}

Na composição das misturas, foram empregadas as combinações de solos contendo a areia, nos teores de 60, 70 e $80 \%$, bem como as argilas amarela e vermelha, nos teores de 20, 30 e 40\%. Os solos e respectivas misturas foram caracterizados geotecnicamente, como segue: (i) solos: massa específica dos grãos (ABNT, 1984 ), granulometria (ABNT, 1984a), limite de liquidez (ABNT, 1984b), limite de plasticidade (ABNT, 1984c), compactação (ABNT, 1986) na energia do ensaio Proctor modificado, índice de suporte Califórnia - ISC (ABNT, 1987) na energia do ensaio Proctor modificado; e (ii) misturas: compactação (ABNT, 1986) e índice de suporte Califórnia (ABNT, 1987), na energia do ensaio Proctor modificado. A mistura que apresentou maior índice de suporte Califórnia foi caracterizada, também, através dos ensaios-limite de liquidez (ABNT, 1984b) e limite de plasticidade (ABNT, 1984C).

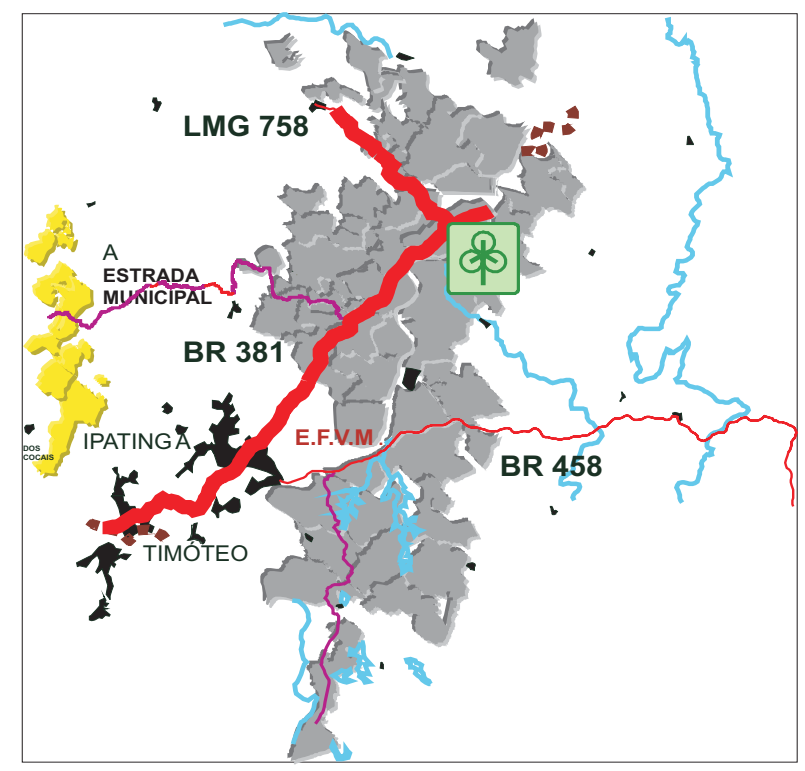

Figura 2 - Localização geográfica da CENIBRA. Figure 2-CENIBRA's geographical localization.

Revista Árvore, Viçosa-MG, v.34, n.6, p.1085-1090, 2010 


\section{RESULTADOS E DISCUSSÕES}

Os resultados dos ensaios realizados nos solos e misturas são apresentados, como se segue: (i) Tabela 1 , onde se resumem os resultados dos ensaios de caracterização geotécnica dos solos analisados, bem como se apresentam as suas classificações, segundo o sistema adotado pelo Transportation Research Board dos Estados Unidos (TRB), também adotado pelo Departamento Nacional de Infraestrutura de Transportes (DNIT, 2006); (ii) Tabela 2, onde se mostram os resultados dos ensaios de compactação e ISC para os solos e respectivas misturas; (iii) Tabela 3, onde se exibem os resultados dos limites de Atterberg da mistura areia e argila, que apresentou o melhor resultado de resistência mecânica, que foi constituída por $80 \%$ de areia e $20 \%$ de argila amarela.

Considerando os dados apresentados na Tabela 1, nota-se que os solos argilosos não exibem composições granulométricas muito diferenciadas, podendo relacionar as diferenças observadas nos seus parâmetros de plasticidade provavelmente à natureza dos argilominerais presentes neles, embora essa determinação não tenha sido objeto de estudo neste trabalho.

Com relação aos resultados dos ensaios ISC obtidos nos solos naturais e suas misturas (Tabela 2), observou-se que esse parâmetro variou de 22 a 29\%, e a expansão medida nesse ensaio situou-se abaixo de $0,13 \%$. Do ponto de vista de suporte e expansão, parâmetros esses determinados na energia de compactação do ensaio Proctor modificado, todos os solos atenderam às exigências de projeto de pavimentos flexíveis, tanto para a camada de reforço do subleito quanto para a sub-base, segundo as exigências do DNIT (2006). No entanto, vale destacar que, em geral, as faixas recomendadas para esses parâmetros se referem à energia do ensaio Proctor intermediário.

Tabela 1 - Caracterização geotécnica e classificação dos solos.

Table 1 - Geotechnical characterization and classification of soils.

\begin{tabular}{|c|c|c|c|c|}
\hline \multirow{2}{*}{\multicolumn{2}{|c|}{ Ensaios de caracterização }} & \multicolumn{3}{|c|}{ Solos } \\
\hline & & Argila amarela & Argila vermelha & Areia \\
\hline Limite de liquid & & 47 & 82 & - \\
\hline Limite de plastici & (\%) & 27 & 46 & - \\
\hline Índice de plastici & (\%) & 20 & 36 & \\
\hline Peso específico dos g & $\left(\mathrm{kN} / \mathrm{m}^{3}\right)$ & 25,43 & 25,85 & 25,32 \\
\hline \multirow{4}{*}{$\begin{array}{l}\text { Granulometria } \\
\text { (\% em peso Que passa) }\end{array}$} & Argila & 77 & 68 & 8 \\
\hline & Silte & 5 & 3 & 1 \\
\hline & Areia & 18 & 29 & 91 \\
\hline & Pedregulho & 0 & 0 & 0 \\
\hline \multicolumn{2}{|c|}{ Classificação TRB } & A-7-6 (13) & A-7-5 (19) & A-3 (0) \\
\hline
\end{tabular}

Tabela 2 - Resultados dos ensaios de compactação ( $\mathrm{h}_{\mathrm{ot}}$ : umidade ótima; $\mathrm{g}_{\text {smax }}$ : peso específico aparente seco máximo) e índice de suporte Califórnia (ISC) realizados na energia de compactação do ensaio Proctor Modificado.

Table 2 - Data from compaction ( $h_{o t}$ : optimum moisture content; $g_{\text {smax }}$ : maximum dry density) and California bearing ratio (CBR) tests performed at the modified Proctor compaction effort.

\begin{tabular}{|c|c|c|c|c|}
\hline \multirow[t]{2}{*}{ Solos e misturas } & \multicolumn{4}{|c|}{ Parâmetros de compactação e suporte } \\
\hline & $\mathrm{g}_{\mathrm{smax}}\left(\mathrm{kN} / \mathrm{m}^{3}\right)$ & $\mathrm{h}_{\mathrm{ot}}(\%)$ & ISC $\%$ & Expansão $_{\text {ISC }}(\%)$ \\
\hline Argila Amarela & 15,61 & 24,19 & 25 & 0,13 \\
\hline Argila Vermelha & 16,63 & 21,04 & 22 & 0,13 \\
\hline Areia & 16,55 & 4,09 & 29 & 0,03 \\
\hline $60 \%$ areia $+40 \%$ argila amarela & 18,38 & 13,67 & 30 & 0,02 \\
\hline $70 \%$ areia $+30 \%$ argila amarela & 18,97 & 11,66 & 60 & 0,06 \\
\hline $80 \%$ areia $+20 \%$ argila amarela $*$ & 19,26 & 10,72 & 63 & 0,09 \\
\hline $60 \%$ areia $+40 \%$ argila vermelha & 19,16 & 11,48 & 54 & 0,00 \\
\hline $70 \%$ areia $+30 \%$ argila vermelha & 19,11 & 11,50 & 62 & 0,12 \\
\hline $80 \%$ areia $+20 \%$ argila vermelha & 18,48 & 13,41 & 50 & 0,06 \\
\hline
\end{tabular}

* Maior capacidade de carga dentre as misturas ensaiadas.

* Greater payload of the mixtures tested.

Revista Árvore, Viçosa-MG, v.34, n.6, p.1085-1090, 2010 
Tabela 3 - Limites de Atterberg da mistura 80\% areia + 20\% argila amarela.

Table 3 -Atterberg limits of the $80 \%$ sand $+20 \%$ yellow clay mixture.

\begin{tabular}{lc}
\hline Parâmetros & $\begin{array}{c}\text { Mistura (80\% areia + } \\
\text { 20\% argila amarela) }\end{array}$ \\
\hline Limite de liquidez (\%) & 25 \\
Limite de plasticidade (\%) & 16 \\
Índice de plasticidade (\%) & 9 \\
\hline
\end{tabular}

Cabe aqui, entretanto, ressaltar que, mesmo atendendo a certas exigências de projeto, deve-se ter em mente o problema de construir uma camada de pavimento com material essencialmente argiloso ou arenoso, conforme relato de Senço (1997), como segue: (i) uma camada argilosa quando seca e adequadamente compactada oferece elevada resistência, mas em período de chuva, devido à absorção de água, a sua resistência ao cisalhamento pode reduzir drasticamente, causando sérios defeitos na pista, além de torná-la muito escorregadia; (ii) se a camada for construída somente com um solo arenoso, pode-se referir à dificuldade de compactação, bem como à necessidade de providenciar confinamento lateral da massa de solo; também, em época de chuva, pode-se referir ao fato de que a areia é facilmente carreada pela água, desagregando-se e formando areiões que dificultam a trafegabilidade dos veículos.

Percebe-se, pois, que a mistura de um solo arenoso com outro argiloso é, muitas vezes, uma solução adequada para produzir um material de bom desempenho como revestimento primário e camada de reforço de pavimentos de rodovias. Segundo Baesso e Gonçalves (2003), um bom revestimento primário é aquele composto por material cuja mistura desejada apresenta, na sua constituição, agregado graúdo, areia e finos. Analisando os resultados contidos na Tabela 2, observa-se que a mistura que gerou maior resistência mecânica foi a correspondente a $80 \%$ de areia com $20 \%$ de argila amarela, alcançado-se um ISC de 63\% e uma expansão medida nesse ensaio de $0,09 \%$, na energia de compactação do ensaio Proctor modificado.

As condições de plasticidade da mistura de $80 \%$ de areia com $20 \%$ de argila foram, também, determinadas e, segundo o DNIT (2006), consideradas satisfatórias para aplicações como camadas de reforço e sub-base de pavimentos rodoviários, com limite de liquidez igual a 25\% e índice de plasticidade igual a 9\%, conforme apresentado na Tabela 3. Segundo o DNIT (2006), vale destacar que essa mistura pode ser utilizada, também, como camada de base de pavimentos flexíveis, nas situações que envolvam número depassadas do eixo-padrão de 8,2 tinferior a $5 \times 10^{6}$ solicitações e equivalente de areia da mistura superior a 30\%. Outras misturas que atingiram patamares semelhantes de suporte e expansão, com ISC igual ou superior a $60 \%$, foram as que empregaram as combinações de $70 \%$ de areia com $30 \%$ de argila vermelha e $70 \%$ de areia com 30\% de argila amarela, como ilustrado na Tabela 2.

Finalizando, sugere-se construir trechos experimentais, que funcionarão como laboratórios de estudos para a avaliação das misturas em serviço, sob as solicitações usuais de tráfego e meio ambiente.

\section{CONCLUSÕES}

Através dos resultados de laboratório, verificou-se obom desempenho mecânico de todas as misturas analisadas, em termos do parâmetro ISC. Destaca-se que a mistura de $80 \%$ de areia com $20 \%$ de argila amarela apresentou a melhor capacidade de carga, com ISC de 63\%, podendo destacar o seu potencial como material de construção rodoviária nas funções de melhoria de subleito, camadas de reforço e sub-base e, sob determinadas condições (por exemplo, baixo volume de tráfego e equivalente de areia superior a 30\%), camada de base de pavimentos flexíveis.

\section{REFERÊNCIAS}

ASSOCIAÇÃO BRASILEIRA DE NORMAS TÉCNICAS - ABNT. NBR 7181/84 - Solo Análise granulométrica procedimento. Rio de Janeiro: 1984a. 13p.

ASSOCIAÇÃOBRASILEIRADE NORMAS TÉCNICAS - ABNT. - NBR 6459/84 - Solo - Determinação do limite de liquidez. Rio de Janeiro: 1984b. 6p.

ASSOCIAÇÃO BRASILEIRA DE NORMAS TÉCNICAS - ABNT. NBR 7180/84 - Solo Determinação do limite de plasticidade, Rio de Janeiro: 1984c. 3p.

ASSOCIAÇÃO BRASILEIRA DE NORMAS TÉCNICAS - ABNT. - NBR 6508/84 - Grãos de solos que passam na peneira de $\mathbf{4 , 8}$ mm - Determinação da massa específica. Rio de Janeiro: 1984d. 8p.

ASSOCIAÇÃOBRASILEIRADE NORMAS TÉCNICAS - ABNT. - NBR 7182/84 - Solo - Ensaio de compactação. Rio de Janeiro: 1986. 10p.

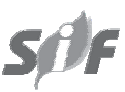

Revista Árvore, Viçosa-MG, v.34, n.6, p.1085-1090, 2010 
ASSOCIAÇÃOBRASILEIRADE NORMAS TÉCNICAS - ABNT. - NBR 9895/87 - Solo - Índice de suporte Califórnia. Rio de Janeiro: 1987. 14p.

BAESSO, D. P.; GONÇALVES, F. L. R. Estradas rurais - técnicas adequadas de manutenção. Florianópolis: Departamento Estadual de Infra-Estrutura, 2003. 204p.

DEPARTAMENTO NACIONAL DE INFRAESTRUTURA DE TRANSPORTES - DNIT.

Manual de pavimentação. Rio de Janeiro: Ministério dos Transportes, 2006. 274p.

LIMA, D. C. Algumas considerações relativas a aspectos da estabilização dos solos, em particular à estabilização solo-cal. 1981. $171 \mathrm{f}$.

Dissertação (Mestrado em Geotecnia) - Escola de Engenharia de São Carlos, São Carlos, 1981.

LIMA, D. C. et al. A experiência da UFV no emprego de estabilizantes químicos em estradas florestais. In: SIMPÓSIO BRASILEIRO SOBRE COLHEITAE TRANSPORTE FLORESTAL, 6., 2003, Belo Horizonte. Anais... Belo Horizonte: Sociedade de Investigações Florestais (SIF), 2003. p.69-117.
MILLER, E. A.; SOWERS, G. F. The Strength characteristics of soil-aggregate mixtures.

Highway Research Board, Soil Stabilization Studies, n.183, p.1-23, 1957.

SENÇO, W. Manual de técnicas de pavimentação. São Paulo: Pini, 1997. v.2. $671 \mathrm{p}$.

SOUTO SILVEIRA, E. B.; SILVEIRA, A. Notas sobre a dosagem dos componentes na estabilização granulométrica. São Carlos/ São Paulo, Escola de Engenharia de São Carlos/ Universidade de São Paulo, 1964. 16p.

(Publicação, 102).

TRINDADE, T. P. et al. Estudo da durabilidade de misturas solo-RBI Grade 81 com vistas à aplicação em estradas florestais e camadas de pavimentos convencionais. Revista Árvore, v.29, n.4, p.591-600, 2005.

VELTEN, R. Z. et al. Caracterização mecânica de misturas solo-escória de alto-forno granulada moída para aplicações em estradas florestais. Revista Árvore, v.30, n.2, p.235-240, 2006. 